\title{
Design of Computer Program to Differentiate between Continuous and Discontinuous Operation in the PWM
}

\author{
Ali H. Al-Obaidly \\ (Department of Electricity, Public Authority for applied Education and Training, Kuwait
}

\section{ABSTRACT}

This research studies the electric performance of the DC motor by writing a computer program to differentiate between two mode of operations in the PWM. This mode of operations are continuous and discontinuous. The aim of this research is design a computer program applicable for any type of DC motor. The computer program is designed to get the operation curves by entering the parameters of any type of DC motors. The designed program is ready to get: 1) the effect of different levels of voltage upon maximum motor current. 2) the effect of frequency levels upon the mode of operations. 3) the relationship between the maximum current load and the time at a different voltages.

Keywords: computer program, performance, DC motor, continuous, discontinuous.

\section{INTRODUCTION}

The control of electric power with power electronic devices has become increasingly important over the last 20 years. Whole new classes of motors have been enable by power electronics, and the future offers the possibility of more effective control of the electric power grid using power electronics. The modern of power electronics began with the introduction of thyristors in the late 1950s. Now there are several types of power devices available for high-power and high-frequency application. The most notable power devices are gate turn-off thyristors, power Darlington transistors, power MOSFETs, and insulated-gate bipolar transistors (IGBTs). Power semiconductor devices are the most important functional elements in all power conversion applications. The power devices are mainly used as switches to convert power from one form to another. They are used in motor control systems, uninterrupted power supplies, high-voltage DC transmission, power supplies, induction heating, and in many other power conversion applications[1].

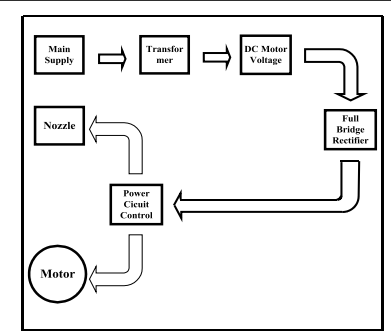

Fig.1:Block Diagram Circuit
The switch mode power supply has several functions[4]:

1- Step down an unregulated DC input voltage to produce a regulated DC output voltage using a buck or step - down converter.

2- Step up an unregulated DC input voltage to produce a regulated DC output voltage using a boost or step-up converter.

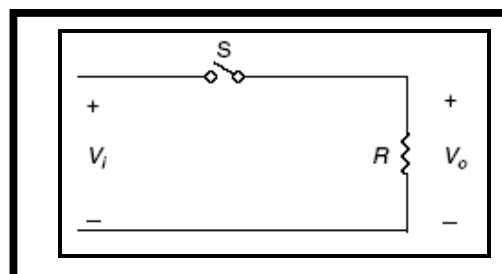

Fig.2: Basic DC-DC Converter.

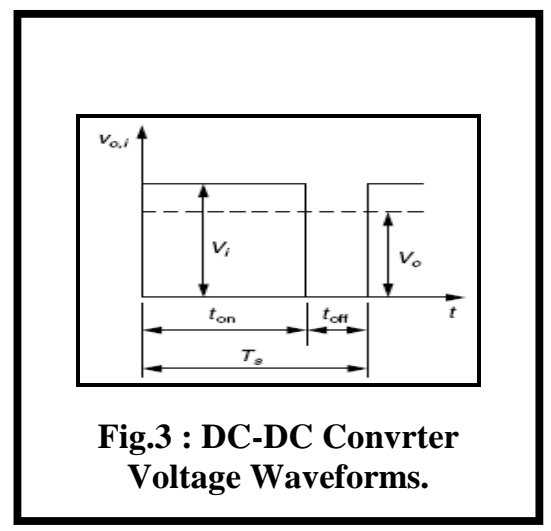




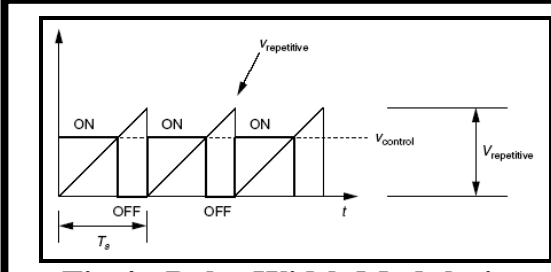

Fig.4 : Pulse Width Modulation Concept.

3- Step down and then step up an unregulated DC input voltage to produce a regulated DC output voltage using a buck-boost converter.

4- Invert the DC input voltage using a Cuk converter.

5- Produce multiple DC output using a combination of SMPS topologies.

The regulation of the average output voltage in a DC-DC converter (Fig.2) is a FUNCTION of the on-time $t_{\text {on }}$ of the switch, the pulse width, and the switching frequency $f_{s}$ as illustrated in Fig.3. Pulse width modulation (PWM) is the most widely used method of controlling the output voltage. The PWM concept is illustrated in Fig.4. The output voltage control depends on the duty ratio $D$. The duty ratio is defined

Where;

D duty ratio

ton on time

Ts switching frequency time period

As based on the on-time $t_{\text {on }}$ of the switch and the switching period $T_{g}$. PWM switching involves comparing the level of a control voltage $v_{\text {control }}$ to the level of a repetitive waveform as illustrated in Fig.4[3]. The on-time of the switch is defined as the portion of the switching period where the value of the repetitive waveform is less than the control voltage. The switching period (switching frequency) remains constant while the control voltage level is adjusted to change the on-time and therefore the duty ratio of the switch. The switching frequency is usually chosen above $20 \mathrm{kHz}$ so the noise is outside the ratio range[3-4]. In this thesis the switching frequency range used is up to $1 \mathrm{~K} \mathrm{~Hz}$ for the DC Chopper. DC-DC converters operate in one of two modes depending on the characteristics of the output current [2-3]:

1- Continuous conduction

2- Discontinuous conduction

The continuous-conduction mode is defined by continuous output current (greater than zero) over the entire switching period, whereas the discontinuous conduction mode is defined by discontinuous output current (equal to zero) during any portion of the switching period. Each mode is discussed in relationship to the buck converter.

\section{PROBLEM FORMULATION}

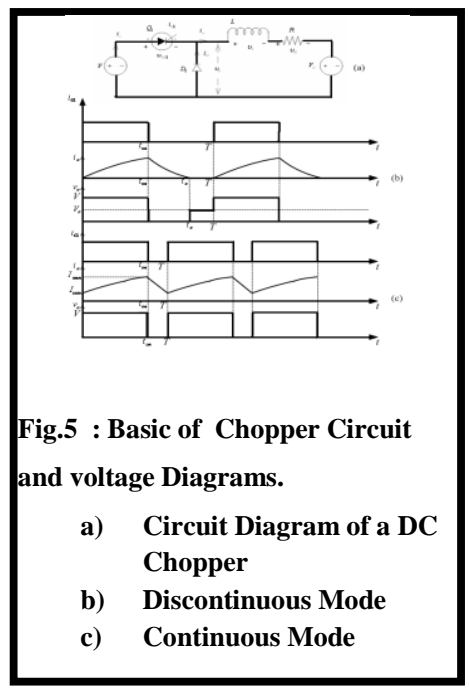

Fig.5 illustrate two mode of operation (continuous \& discontinuous). In the circuit of ( Fig.5a), the equation of Kirchhoff's Voltage Law (KVL) is

$-v_{o}+v_{L}+v_{R}+V c=0$

Where

$v_{o}=$ output voltage

$v_{L}=$ inductance voltage

$v_{R}=$ resistance voltage

$V c=\mathrm{DC}$ source

$\frac{d i_{o}}{d t}+\frac{R}{L} i_{o}=\frac{v_{o}-V c}{L}$

$i_{o}=\frac{V-V c}{R}\left(1-\varepsilon^{-t_{o n} / \tau}\right)+I_{\min } \varepsilon^{-t_{o n} / \tau}$

$0 \leq t \leq t_{\text {on }}$

Where

$\mathrm{V}$ = supply voltage

$I_{\min }=$ minimum current

$t_{\text {on }}=$ on time

$\tau=\frac{L}{R}$

$\varepsilon=$ exponential

$\boldsymbol{I}_{\max }=i_{o}=\frac{V-V c}{R}\left(1-\varepsilon^{-t_{o n} / \tau}\right)+I_{\min } \varepsilon^{-t_{o n} / \tau}$

$\frac{d i_{o}}{d t}+\frac{R}{L} i_{o}=-\frac{V c}{L}$

Where

$t=t-t_{\text {on }}$

At $\grave{t}=0^{+}, i_{o}=\boldsymbol{I}_{\max }$ 


$$
\begin{gathered}
i_{o}=\frac{-V c}{R}\left(1-\varepsilon^{-t / \tau}\right)+I_{\max } \varepsilon^{-t / \tau} \\
t_{o n} \leq t \leq T \\
\text { At } t=T-t_{\text {on }}, \text { or } t=T, i_{o}=I_{\min } \\
i_{\min }=-\frac{V c}{R}\left(1-\varepsilon^{-\left(T-t_{o n}\right)^{\prime} / \tau}\right)+I_{\max } \varepsilon^{-\left(T-t_{o n}\right)^{\prime}} \\
\text { Solving the previous equations we gt } \\
I_{\max }=\frac{V}{R} \frac{\left(1-\varepsilon^{-t_{o n} / \tau}\right)}{\left(1-\varepsilon^{-T / \tau}\right)}-\frac{V c}{R} \\
I_{\min }=\frac{V}{R} \frac{\left(\varepsilon^{t_{o n} / \tau}-1\right)}{\left(\varepsilon^{T / \tau}-1\right)}-\frac{V c}{R} \\
I_{\max }=I_{\min }=\frac{V-V c}{R}(12) \\
\frac{V c}{V}=\frac{\varepsilon^{\left(t_{o n}^{x} / T\right)(T / \tau)}-1}{\varepsilon^{(T / \tau)}-1} \\
\text { or } \\
m=\frac{\varepsilon^{\rho \sigma}-1}{\varepsilon^{\sigma}-1}
\end{gathered}
$$$$
i_{\min }=-\frac{V c}{R}\left(1-\varepsilon^{-\left(T-t_{o n}\right)^{\prime} / \tau}\right)+I_{\max } \varepsilon^{-\left(T-t_{o n}\right)^{\prime} / \tau}
$$

Solving the previous equations we get

where

$$
m=\frac{V c}{V}
$$

$m=$ the ratio between main supply and DC source.

$$
\rho=\frac{t_{o n}^{x}}{T}
$$

Where

$t_{o n}^{x}=$ the time at which $I_{\min }=0$

$\rho=$ the ratio between changeover point and time period.

$\sigma=$ the ratio between time period and $\tau$.

$$
\sigma=\frac{T}{\tau}
$$

$I_{\min }=0$, then from equation 5 ,

$$
I_{\text {max }}=\frac{V-V c}{R}\left(1-\varepsilon^{-t_{\text {on }} / \tau}\right): 0 \leq i \leq t_{\text {on }}^{x}
$$

and from equation 8 and 18

$$
i_{o}=\frac{-V c}{R}\left(1-\varepsilon^{-t / \tau}\right)+\frac{V-V c}{R}\left(1-\varepsilon^{-t_{o n} / \tau}\right) \varepsilon^{-t / \tau}
$$

$$
t \text { on } \leq \grave{t} \leq T
$$

$t_{x}=\tau \ln \left\{\varepsilon^{t_{o n} / \tau}\left[1+\frac{V-V c}{V c}\left(1-\varepsilon^{-t_{o n} / \tau}\right)\right]\right\}$

\section{DESIGN THE COMPUTER PROGRAM}

Fig. 6 illustrates the flowchart that has drawn depending on the motor parameters and the equations( 1-4):
1) $\boldsymbol{I}_{\max }=i_{o}=\frac{V-V c}{R}\left(1-\varepsilon^{-t_{o n} / \tau}\right)+I_{\min } \varepsilon^{-t_{o n} / \tau}$

2) $i_{\min }=-\frac{V c}{R}\left(1-\varepsilon^{-\left(T-t_{o n}\right)^{\prime \prime} / \tau}\right)+I_{\max } \varepsilon^{-\left(T-t_{o n}\right)^{\prime \prime} / \tau}$

3)

$$
i_{o}=\frac{-V c}{R}\left(1-\varepsilon^{-i / \tau}\right)+\frac{V-V c}{R}\left(1-\varepsilon^{-t_{o n} / \tau}\right) \varepsilon^{-i / \tau}
$$

$t$ on $\leq t \leq T$

4)

$$
t_{x}=\tau \ln \left\{\varepsilon^{t_{o n} / \tau}\left[1+\frac{V-V c}{V c}\left(1-\varepsilon^{-t_{o n} / \tau}\right)\right]\right\}
$$

The flowchart is designed to get two mode of operation (continuous and discontinuous) for the motor in the pulse width modulation (PWM).

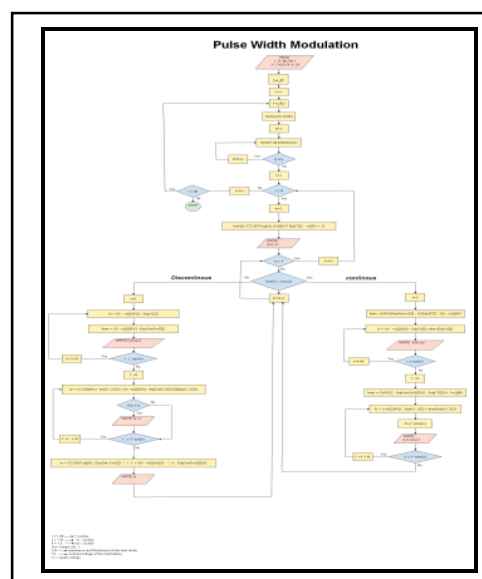

Fig.6: Flow Chart Diagram

Fig.7 illustrates the computer program that has designed to be applicable for any type of motors. the computer program has written according to the steps that have drawn in the flowchart.

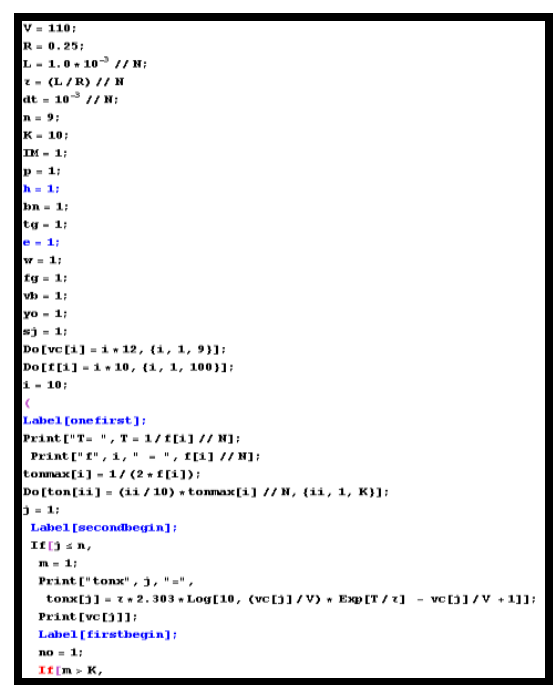



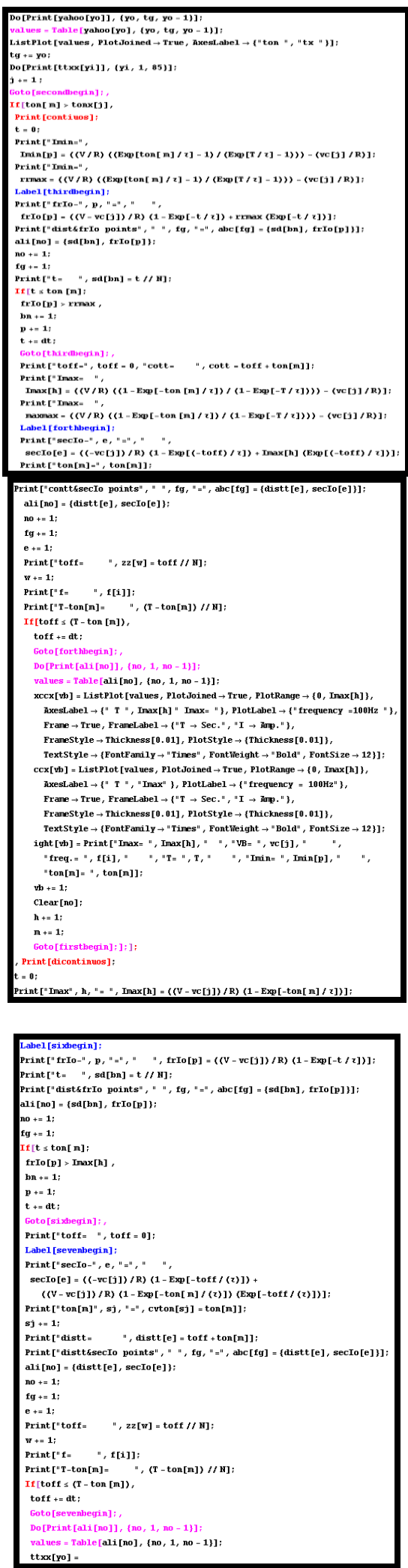

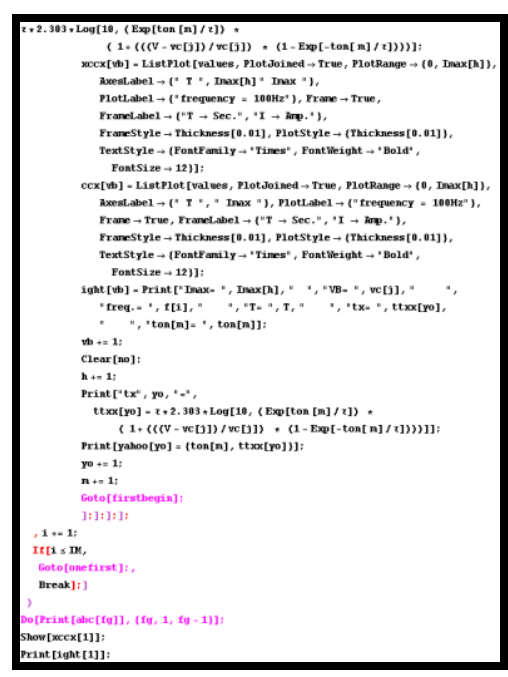

\section{RESULTS \& DISCUSSIONS}

\subsection{Relationship Between I And T At A}

\section{Different Voltages}

The curves in Fig. 8 have obtained from the computer program as a result and represents the relation between motor currents and the time. Farther more, its represents the effect of the different voltages upon the motor current.

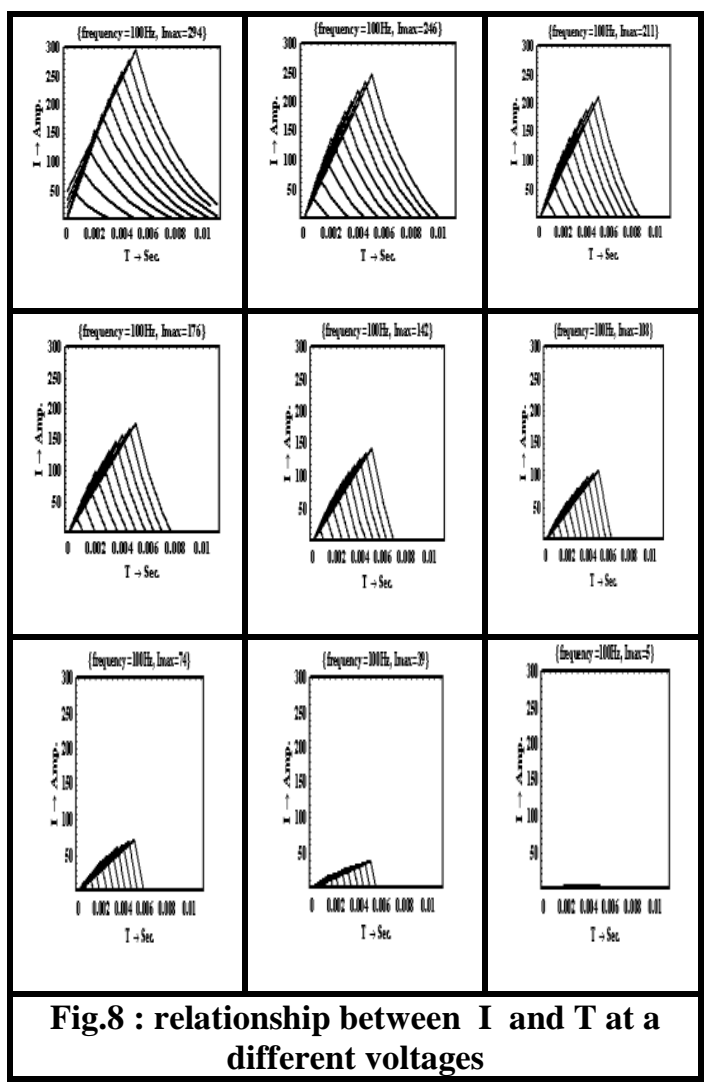

\section{CONCLUSION}

The computer program has designed to obtain of two mode of operation for the motor in the PWM 
continuous and discontinuous. The computer program is applicable for any type of motor that has parameters (voltage (V), current (I) and inductance (L)). As a result, Fig.8 illustrates that the current is reducing when the voltage is increasing and as the current decreases ton is decreasing.

\section{REFERENCES}

[1] T. L. Skvarenina, The Power Electronics hand book, 2002

[2] J. P. Agrawal, Power Electronics:Theory and Design, ed Prentice-Hall, Upper Saddle River,NJ, 2001.

[3] N. U. Mohan, T. M., and Robbins, in Power Electronics: Converters, Application, and Design, 2 ed: John Wiley \& Sons, New York, 1995.

[4] R. Venkat, "Switch Mode Power Supply," University of Technology, Sydney, Australia, March 1, 2001. 